
\title{
28 Research Suare \\ Tear-drop Fracture of the Axis: Non-operative Treatment of Two Cases : Case Report
}

Adnene Benammou ( $\square$ adnene.benammou@gmail.com )

Charles Nicolle Hospital: Hopital Charles Nicolle https://orcid.org/0000-0001-7735-2213

Ahmed Elloumi

Charles Nicolle Hospital: Hopital Charles Nicolle

Mohamed Amin Jaouadi

Charles Nicolle Hospital: Hopital Charles Nicolle

Mehdi Bellil

Charles Nicolle Hospital: Hopital Charles Nicolle

Mondher Kooli

Charles Nicolle Hospital: Hopital Charles Nicolle

\section{Research Article}

Keywords: Fracture, Tear-drop, Axis, Upper cervical spine, Case report

Posted Date: November 18th, 2021

DOI: https://doi.org/10.21203/rs.3.rs-766353/v1

License: (c) (1) This work is licensed under a Creative Commons Attribution 4.0 International License.

Read Full License 


\section{Abstract}

Tear-drop fracture of the axis are rare. It is characterized by a fracture of the anterior-inferior corner of the $\mathrm{C} 2$ body. The mechanism is usually in extension which is different from the tear-drop of lower cervical spine. We report two cases of adults who sustained a road traffic accident. They did not have any neurological deficit. The diagnosis was made on radiological examination. They both were treated conservatively with rigid immobilization and recovered well. Tear-drop fracture of the axis are usually stable. Imagery is the key of the diagnosis. Neurological deficit is rare. Conservative management usually give good outcome for non-complicated cases.

\section{Introduction:}

Tear-drop fractures of cervical spine are rare. Those involving the axis are extremely rare. They manifest by a fracture of the anterior inferior corner of the $\mathrm{C} 2$ body. This type of fracture occurs in elderly following minor trauma or in middle-aged population flowing high energy trauma. The mechanism, the stability, the complications and the treatment are different from tear-drop fracture of the lower cervical spine. We present two cases of patient with tear-drop fracture of the axis. We aim to study by means of our cases the management strategy of this type of fracture.

\section{Case Report:}

\section{Case 1}

A 64-year-old male, with no medical history, was a car-driver who was in a road traffic accident. He presented to the emergency department with severe neck pain. There was no associated head trauma. At the time of the examination the patient was fully conscious with a Glasgow Coma Scale at 15 with no respiratory or hemodynamic distress and had a neck pain with inability to move the neck. Motor and sensory examination were normal. Planters were flexor. Hoffman sign was negative. The patient was immobilized in a rigid cervical collar. Lateral radiograph of cervical spine showed a tear drop fracture of C2 vertebrae (Figure 1a). A Computed Tomography (CT) scan was conducted and showed an avulsion of the anterior inferior portion of C2 (Figure 1b). The CT did not show any posterior displacement of the C2 vertebrae. The retained diagnosis was axis tear-drop without neurological deficit. The decision was to manage the patient conservatively with a rigid cervical immobilization for 6 weeks. After 6 weeks, we noted a full recovery without any complications.

\section{Case 2}

A 49-year-old man, with no medical history, sustained a traffic road accident. The patient presented to the emergency room with sever neck pain. At the time of the examination, the patient was fully conscious with a Glasgow Coma Scale at 15 without any other distress. The patient could not move his neck. Motor and sensory examination were normal. The patient was immobilized in a rigid collar and had a full body 
CT. The CT showed a fracture of the anterior inferior wedge of C2 (Figure 2). The retained diagnosis was a tear-drop fracture of $\mathrm{C} 2$ without neurological deficit. We decided to manage the patient conservatively with a rigid immobilization for 6 weeks. After 6 weeks, the patient fully recovered with no complications.

\section{Discussion:}

Tear-drop fracture of the axis is an avulsion of the anterior inferior angle of the $\mathrm{C} 2$ vertebrae. This injury occurred in $3,2 \%$ of all fractures of the axis in the Roy-Camille series (1). The strength of our case report is that it is about 2 patients both treated conservatively. The limitation is the short follow-up. This fracture differs from lower cervical spine fracture by its mechanism which is an extension for $\mathrm{C} 2$ while its flexion for the lower cervical spine (2). Road traffic are the most common circumstance in the study of Hu et al. (2). Neurological deficit is rare (3). Half of the tear-drop injury are associated with other level injuries which may be the cause of neurological deficit $(1,4)$. This type of fractures is usually stable since posterior elements are intact (5).

Diagnosis can be made with lateral radiography of the cervical spine (6). CT-scan is the ideal investigation. Lingering over indirect signs of instability should be made: widening of the interspinous distance at the site of injury, narrowing of the disc space resulting of the damage to the intervertebral disc, loss of parallelism due to subluxation of the facet joints as a result of disruption of their capsules, posterior displacement of the vertebral body (greater than $3 \mathrm{~mm}$ at the CT-scan (7)) which indicates disruption of the posterior longitudinal ligament and the presence of vertebral soft-tissue widening which is evidence of anterior longitudinal damage(5). MRI can be helpful for the diagnosing an unstable injury especially with high velocity trauma, neurological deficit and soft tissue swelling (5). In our cases, we did not explore patients with MRI since there was no neurological deficit or any sign of instability in the CTscan. The treatment of tear-drop axis fracture is controversial. All authors agree that a neurological deficit is an indication of surgical treatment with decompression and fusion $(2,3,6-9)$. Agrawal et al. (6), Korres et al. (9), Watanabe et al. (3), Hu et al. (2) and Boran et al. (5) chose to manage conservatively stable tear drop fractures of the axis. Ma et al. chose a surgical treatment with anterior reduction, discectomy, bone grafting and instrumentation for a huge tear-drop fracture of the axis (8). Vialle et al. treated a stable teardrop fracture of the axis without neurological deficit with a posterior fusion (7). The authors argument was that there was medullary canal narrowing at the level of C2 without any anomaly of the C2-C3 intervertebral disc. The outcome of this fracture treated conservatively or surgically is usually good (2). In our cases, the conservative treatment lead to a good outcome for stable fractures with no neurological deficit. Both our patients were satisfied with the treatment they received and their outcome.

\section{Declarations}

1. Funding: 


\section{Conflict of interest:}

The authors declare no conflict of interest.

\section{Ethics approval:}

not applicable

\section{Consent to participate:}

not applicable

\section{Consent for publication:}

Informed consent was obtained from both patients described in this report.

\section{Availability of data and material:}

Data sharing not applicable to this article as no datasets were generated or analyzed during the current study.

\section{Code availability:}

not applicable

\section{Authors' contributions:}

The authors confirm contribution to the paper as follows: study conception and design: $A B$; data collection: $A B, M A J$; analysis and interpretation of results: $A B, A E$.; draft manuscript preparation: $A B, M B$, MK. All authors reviewed the results and approved the final version of the manuscript.

\section{References}

1. Korres DS, Zoubos AB, Kavadias K, Babis GC, Balalis K. The "tear drop » (or avulsed) fracture of the anterior inferior angle of the axis. Eur Spine $J$ Off Publ Eur Spine Soc Eur Spinal Deform Soc Eur Sect Cerv Spine Res Soc. 1994;3(3):151-4. 
2. Hu Y, Kepler CK, Albert TJ, Hann S, Ma W-H, Yuan Z-S, et al. Conservative and Operative Treatment in Extension Teardrop Fractures of the Axis. Clin Spine Surg Spine Publ. févr 2016;29(1):E49-54.

3. Watanabe M, Sakai D, Yamamoto Y, Sato M, Mochida J. Clinical features of the extension teardrop fracture of the axis: review of 13 cases: Clinical article. J Neurosurg Spine. juin 2011;14(6):710-4.

4. Motsitsi NS, Bomela LN. Tear-drop Fractures of the Cervical Spine. East and Central African Journal of Surgery. août 2009;

5. Boran S, Hurson C, Gul R, Higgins T, Poynton A, O’Byrne J, et al. Functional outcome following teardrop fracture of the axis. Eur J Orthop Surg Traumatol. août 2005;15(3):229-32.

6. Agrawal A, Malleswara Rao G. Isolated tear-drop fracture of the axis without neurological deficits. Indian J Neurotrauma. juin 2014;11(1):68-70.

7. Vialle R, Schmider L, Levassor N, Rillardon L, Drain O, Guigui P. Fracture «tear-drop » en extension de I'axis. Rev Chir Orthopédique Réparatrice Appar Mot. mars 2004;90(2):152-5.

8. Ma L, Yang Y, Gong Q, Ding C, Liu H, Hong Y. Anterior Reduction, Discectomy, and Three Cortical lliac Bone Grafting With Instrumentation to Treat A Huge Tear Drop Fracture of the Axis: A Case Report and Literature Review. Medicine (Baltimore). avr 2016;95(15):e3376.

9. Korres DS, Papagelopoulos PJ, Mavrogenis AF, Sapkas GS, Patsinevelos A, Kyriazopoulos P, et al. Multiple fractures of the axis. Orthopedics. oct 2004;27(10):1096-9.

\section{Figures}



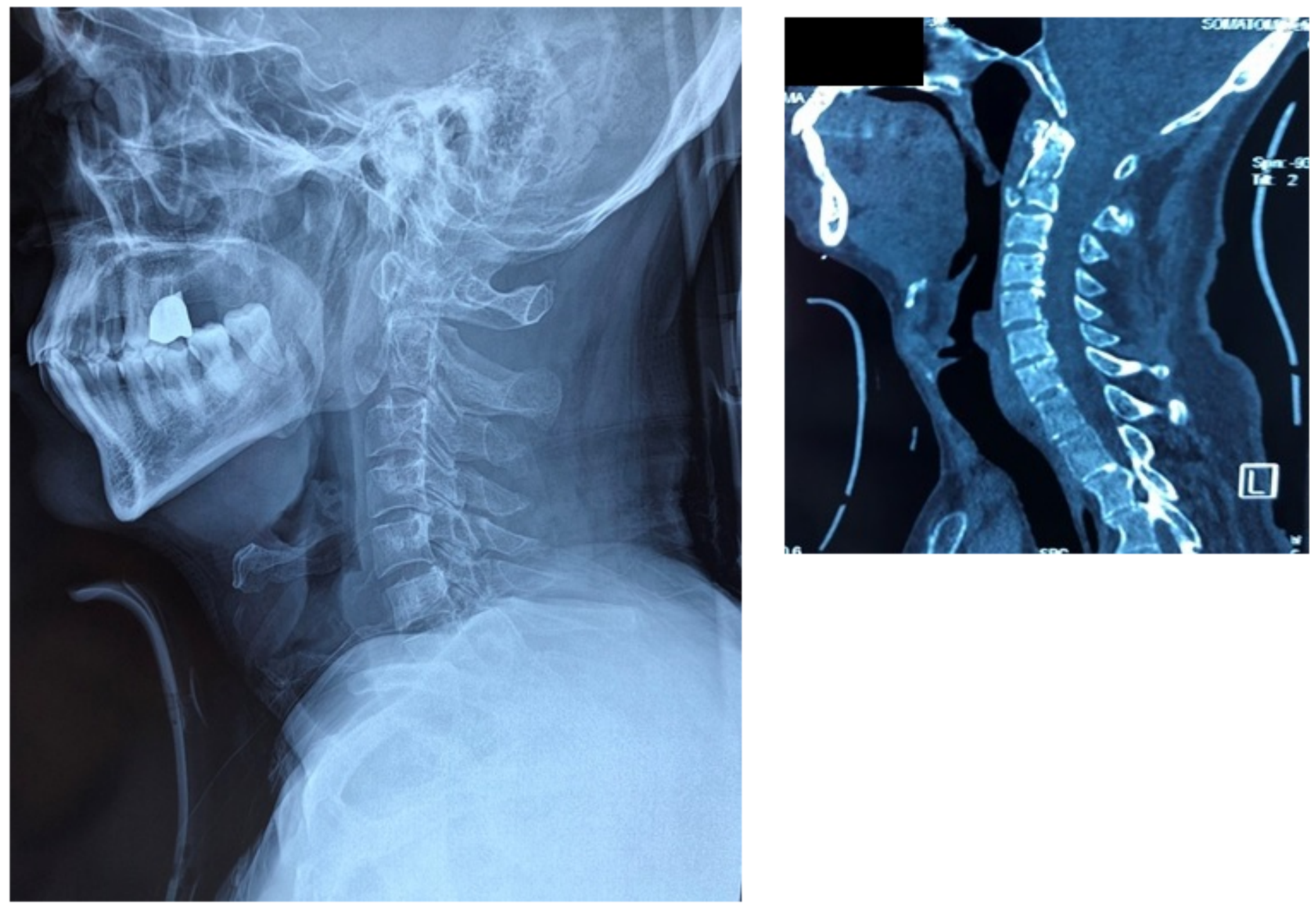

\section{Figure 1}

64-year-old who sustained a road traffic accident. a: Lateral radiography of cervical spine showing a teardrop fracture of C2. b: Sagittal view of C2 showing an avulsed anterior inferior corner of C2 without posterior element lesion or $\mathrm{C} 2-\mathrm{C} 3$ subluxation.

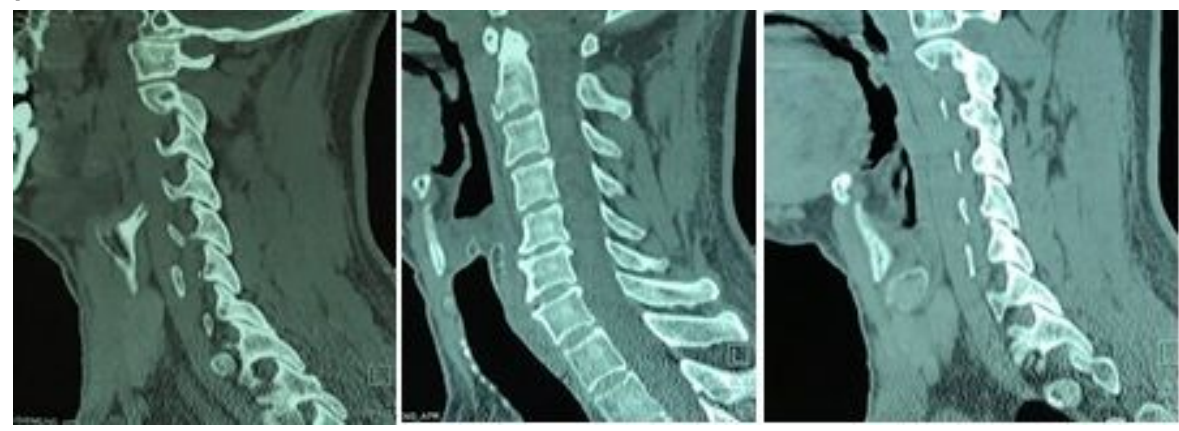

Figure 2

49-year-old male who sustained a road traffic accident: Sagittal reconstruction of CT-scan showing a tear drop fracture of $\mathrm{C} 2$ without any other injury. 


\section{Supplementary Files}

This is a list of supplementary files associated with this preprint. Click to download.

- carechecklist.docx 